\title{
Effects of word frequency on individual-item and serial order retention: Tests of the order-encoding view
}

\author{
PAUL S. MERRITT \\ Texas A\&M University, Corpus Christi, Texas \\ EDWARD L. DELOSH \\ Colorado State University, Fort Collins, Colorado \\ and \\ MARK A. MCDANIEL \\ Washington University, St. Louis, Missouri
}

\begin{abstract}
The order-encoding view of the word frequency effect proposes that low-frequency (LF) items attract more attention to the encoding of individual-item information than do high-frequency (HF) items, but at the expense of order encoding (DeLosh \& McDaniel, 1996). When combined with the assumption that free recall of unrelated words is organized according to their original order of presentation, this view explains the finding that HF words are better recalled than LF words in pure lists but that, in mixed lists, recall is better for LF words. The present study confirmed that in mixed lists, order memory becomes equivalent for HF and LF words and that the predicted pattern of order memory and recall holds for incidental order-encoding conditions, for longer lists than those used in previous experiments, and for lists with minimal interitem associativity. Moreover, recall from HF lists declined, but recall from LF lists improved, in related-word lists, relative to unrelated-word lists, reversing the usual pure-list free recall advantage for HF words. These results were uniquely predicted by the orderencoding account and favor this view over accessibility, interitem association, and cuing effectiveness explanations of the word frequency effect.
\end{abstract}

A survey of studies in which the effect of natural language word frequency on free recall has been examined reveals an interesting paradox. When one compares free recall performance for pure lists of high-frequency (HF) words (e.g., letter, money, and people) with that for pure lists of low-frequency (LF) words (e.g., comet, diaper, and syringe), there is typically an advantage for HF items (Deese, 1960; DeLosh \& McDaniel, 1996; Duncan, 1974; Gregg, 1976; Gregg, Montgomery, \& Castaño, 1980; J. F. Hall, 1954; May \& Tryk, 1970; Postman, 1970; Sumby, 1963). When lists comprising both HF and LF words are given, however, the HF advantage is eliminated, and a free recall advantage for LF items is often observed (DeLosh

Portions of Experiment 2 were presented at the April 1998 Joint Convention of the Western Psychological Association and Rocky Mountain Psychological Association, Albuquerque, NM. We thank Howard L. Whiteman for the ad hoc category norms used to generate the stimulus material for Experiment 2, Kenneth Malmberg and Jim Van Overschelde for their extensive comments on previous versions, and Karla Burleson, John Chambers, Jacque Jiron, Josh Joerres, Courtney Rocheleau, and Melissa Scott for their assistance in participant testing. Correspondence concerning this article should be addressed to P. S. Merritt, Department of Psychology, Texas A\&M University, 6300 Ocean Drive Unit 5827, Corpus Christi, TX 78412-5827 (e-mail: paul.merritt@tamucc.edu).
\& McDaniel, 1996; Duncan, 1974; Gregg, 1976; Gregg et al., 1980; May \& Tryk, 1970; for an exception, see Balota \& Neely, 1980). This reversal as a function of list composition appears to be a robust phenomenon and, as such, represents an important theoretical challenge for explanations of the effect of word frequency on free recall.

In developing theoretical accounts of word frequency effects, it is noteworthy that the pattern described above fits within a larger pattern of results in which the effect of a stimulus variable on free recall is reversed or eliminated as a function of list composition. List composition effects include better recall of generated words than of read words in mixed, but not pure, lists (e.g., Mulligan, 2002; Serra \& Nairne, 1993; Slamecka \& Katsaiti, 1987), better recall of perceptually degraded words than of intact words in mixed, but not unmixed, lists (Mulligan, 1999), better recall of bizarre sentences than of common sentences in mixed, but not pure, lists (e.g., McDaniel \& Einstein, 1986; McDaniel, Einstein, DeLosh, May, \& Brady, 1995; McDaniel, DeLosh, \& Merritt, 2000), better recall of humorous sentences than of common sentences in mixed, but not unmixed, lists (Schmidt, 1994), and better recall of orthographically distinct words than of orthographically common words in mixed, but not pure, lists (Hunt \& Elliot, 1980). Interactions with list composition have also been ob- 
served in experiments on memory for weakly associated versus strongly associated word pairs (Hirshman, 1988), spaced versus massed words (e.g., J. W. Hall, 1992), visually versus auditorily presented words (Greene, 1989), concrete versus abstract paragraphs (Ransdell \& Fischler, 1989), simple versus complex pictures (Zucco, Bardesano, \& Cornoldi, 1984), and participant- versus experimenterperformed actions (Engelkamp \& Dehn, 2000; GollyHäring \& Engelkamp, 2003).

\section{The Order-Encoding Account}

In the spirit of parsimony, DeLosh and McDaniel (1996) proposed a general theoretical framework in an attempt to explain several of the effects enumerated above. This framework focuses on the recall of common items (e.g., HF words, intact words, and common sentences) versus unusual items (e.g., LF words, incomplete or degraded words, and bizarre or humorous sentences) as a function of list composition. Based on the seminal ideas of Nairne, Riegler, and Serra (1991), the central tenet of this approach is that manipulations of unusualness have differential effects on item versus order encoding. The four primary assumptions of this view are as follows.

1. Individual-item information and organizational information jointly contribute to free recall. This assumption is based on well-established multifactor approaches to memory that distinguish between the processing of individualitem attributes and the processing of relations between items (for reviews, see Hunt \& Einstein, 1981; Hunt \& McDaniel, 1993). Multifactor theories typically propose that the retention of organizational information is beneficial for the generation of retrieval candidates, whereas the retention of individual-item information is beneficial for determining whether an item occurred within the experimental context (Nairne \& Kelley, 2004). As such, these factors can independently but jointly contribute to free recall. Several types of organizational information may contribute to recall, such as category membership (Mandler, 1969), interitem associations (Nelson \& McEvoy, 2000), and order information (the ordinal location or serial position of an item; Healy, 1974; Murdock, 1974). Indeed, several instantiations of the multifactor approach center on the distinction between individual-item information and serial order information (e.g., Estes, 1972; Healy, 1974; Murdock, 1974).

2. Participants tend to encode information about serial presentation order, one type of organizational information. This assumption is based on a number of findings showing that the encoding of presentation order is robust (Hinrichs, 1970; Tulving \& Madigan, 1970; Tzeng, 1976; Underwood, 1969) and is observed under incidental-learning conditions (Tzeng, Lee, \& Wetzel, 1979). Toglia and Kimble (1976) observed, for example, that serial position judgments were as accurate when the order test was unexpected as when the order test was expected. In our view, the encoding of order information may include absolute order information, such as "bus was the first item on the list," and relative order information, such as "dog came before chair." Relative order information could be considered a type of interitem information that pertains to contiguity in the experimental con- text, rather than to semantic relations, perceptual relations (e.g., phonemic, orthographic, or visual), or preexperimental associative relations.

3. Participants often use order information to guide free recall. This assumption is based on numerous findings showing that recall order often corresponds to the original order of presentation (e.g., Kintsch, 1970; Mandler, 1969). Use of a seriation strategy is particularly common when lists of unrelated items are given (Postman, 1972) and has been proposed to be the preferred method for organizing lists up to 50 items in length (Mandler \& Dean, 1969). For present purposes, absolute order information, relative order information, or both could contribute to recall performance by providing an organizational structure and effective memory cues during retrieval.

4. Unusual items have an advantage, relative to common items, in the retention of individual-item information but have a disadvantage in the retention of serial order information. DeLosh and McDaniel (1996) proposed that unusual items draw attentional resources for processing and interpretation. This presumably enhances the elaboration and encoding of individual-item information for unusual items, relative to common items, but may detract from the encoding of serial order information (for similar arguments specific to the generation effect, see Burns, 1992, 1996; Burns, Curti, \& Lavin, 1993; Nairne et al., 1991; Serra \& Nairne, 1993). A number of recent experiments have demonstrated that individual-item information and order information are dissociable. These studies have demonstrated that several factors disrupt order memory independently of item memory, including perceptual interference (Mulligan, 2000a), generation (Mulligan, 2002; Nairne \& Kelley, 2004), and the presence of items very low in frequency (Mulligan, 2001). In all of these studies, the retention of order information was disrupted, with no effect on individual-item retention. Unusualness can be thought of as generally enhancing item memory and disrupting order memory. This disruption may be due to limits of attentional resources or to a disruption of encoding directed at interrelations among list items (e.g., Mulligan, 2000b, 2001). An important point for present purposes is that to our knowledge, only one study has demonstrated the opposing pattern in which enhanced item memory was accompanied by enhanced order memory. Nairne and Kelley used a process dissociation procedure to examine item versus order memory and found that LF words were associated with both superior item and superior order memory. Note, however, that this finding may be related to their unique procedure in which order memory was estimated by asking participants to exclude an item from a given serial position in the study list during recall.

The set of assumptions above accounts for the effects of unusualness on free recall in the following manner. Following from Assumption 4, the encoding of order information should be greater for pure lists of common items than for pure lists of unusual items. Because order information is commonly used to guide free recall (Assumption 3), the common-item advantage in order encoding translates into better free recall performance for common items (presumably overcoming the unusual-item advantage in individual- 
item processing). In mixed lists, on the other hand, order memory for common and unusual items should be equivalent and at a level intermediate to that for pure lists. This reflects interdependence between order memory for common items and order memory for unusual items, given that serial order retention for any one position is necessarily dependent on serial order retention for neighboring positions. Because order memory does not differ in mixed lists, the unusual-item advantage in individual-item processing (Assumption 4) can now be expressed as an advantage in free recall. Thus far, this explanation has been successfully applied to the generation effect (Burns, 1996; Nairne et al., 1991; Serra \& Nairne, 1993), bizarreness effect (McDaniel et al., 2000; McDaniel et al., 1995), word frequency effect (DeLosh \& McDaniel, 1996), and perceptual interference effect (Mulligan, 1999). This account was recently extended to the recall of participant- versus experimenter-performed actions as well (Engelkamp \& Dehn, 2000; Golly-Häring \& Engelkamp, 2003).

\section{Order Encoding and Word Frequency}

As applied to the word frequency effect, the orderencoding account proposes that LF items draw attention for interpretation (e.g., Malmberg \& Nelson, 2003), detracting attention from the encoding of serial order information. As a result, order memory should be better for pure HF lists than for pure LF lists. Because serial order information is used to support a seriation strategy, a preferred output strategy for lists of unrelated items, this would translate into an $\mathrm{HF}$ advantage in recall. Order memory for HF versus LF items should be equivalent in mixed lists, however, allowing the LF word advantage in individual-item information to be expressed as a benefit in free recall. This is precisely the pattern of results that was observed in a series of experiments by DeLosh and McDaniel (1996). When pure lists were compared, there was an HF word advantage in order reconstruction, ${ }^{1}$ input-output correspondence, and free recall. When mixed lists were examined, order memory did not differ as a function of word frequency, but there was an LF word advantage in free recall.

Although DeLosh and McDaniel's (1996) study provides preliminary support for the order-encoding view, there are important limitations to the study that preclude acceptance of this view as a general explanation of word frequency effects. First, in their experiments, they did not directly examine the assumption that order information is routinely encoded and used for free recall, nor did they consider whether word frequency effects are better explained by the differential encoding of order information or the differential use of order information at the time of retrieval (cf. McDaniel et al., 2000; McDaniel et al., 1995). Second, DeLosh and McDaniel's experiments used short word lists of eight items and a testing procedure that may have encouraged greater attention to and encoding of order information than is the case for typical free recall experiments. For more typical free recall experiments, an explanation of frequency effects based on differential preexperimental associations across HF and LF items might be favored (see, e.g., Deese, 1960; Gregg, 1976; Nelson \& Xu, 1995; Stuart \& Hulme, 2000).

In Experiment 1, we addressed these issues by examining whether or not the predicted order memory and free recall dynamics extend to incidental order-encoding conditions and longer lists (than those used by DeLosh $\&$ McDaniel, 1996) that controlled for preexperimental interitem associations. Having verified key assumptions of the order-encoding account and demonstrated that the predictions of this account are not limited to narrow boundary conditions, we then conducted a strong test of the theory by pitting it against traditional explanations of the word frequency effect based on accessibility, interitem associations, and cuing effectiveness. Specifically, Experiments 2A and 2B tested the unique prediction of the order-encoding view that the pure-list HF advantage in free recall will be reversed if learners use an alternative (non-order-based) retrieval strategy.

\section{EXPERIMENT 1}

In the present experiment, we examined whether or not the pattern of order memory and recall performance observed in DeLosh and McDaniel (1996) would generalize to longer lists and incidental order-encoding conditions, conditions that likely do not encourage the encoding and use of order information in free recall. Order reconstruction, input-output correspondence, and free recall were examined for pure and mixed lists of HF and LF words. List length, however, was more typical of free recall experiments: Lists comprised 16 items, rather than 8 items. In addition, the instructions and procedures were similar to those of traditional free recall experiments in that they did not encourage the encoding or use of serial order information. Only one order reconstruction test was administered, and this test was given at the end of the experiment, following the recall test for the final list. Order information was not mentioned until the instructions for the order reconstruction test were presented immediately prior to the test.

Second, in this experiment, we also considered a longstanding account of the word frequency effect. This account suggests that HF, but not LF, words will tend to have preexperimental associations that can be exploited during encoding and recall to enhance performance (e.g., Deese, 1960; Gregg, 1976; Nelson \& Xu, 1995; Stuart \& Hulme, 2000). Apparent support for this account was reported by Nelson and $\mathrm{Xu}$, who constructed lists of HF and LF items that had no direct connections between items and controlled for indirect connections as well. Using these lists, they did not obtain a significant HF advantage in free recall, motivating their conclusion that preexperimental associations among items mediate the word frequency effect. This conclusion is uncertain, however, because Nelson and Xu used mixed lists of HF and LF items and mixed lists themselves are known to eliminate the HF advantage found with pure lists. It is, therefore, of theoretical importance to determine whether the usual HF advantage in free 
recall is eliminated in pure lists with low preexperimental interitem associations.

To examine this issue, we assembled lists with minimal interitem associativity. If the word frequency effect is mediated by preexperimental associations (Deese, 1960; Gregg, 1976; Nelson \& Xu, 1995; Stuart \& Hulme, 2000), the free recall advantage for HF items in pure lists should be eliminated. Neither pure nor mixed lists should yield better recall for HF words than for LF words. In contrast, if the order-encoding explanation holds for the longer lists used here, the interitem associativity of the lists should have no bearing on the word frequency effect, and the pure-list recall advantage for HF items should be obtained. We would also expect better order reconstruction and input-output correspondence for pure HF lists than for pure LF lists, on the basis of the idea that HF words gain their advantage in free recall through superior encoding of serial order information (rather than through preexperimental associations among HF words). Finally, the order-encoding explanation anticipates no order memory differences in mixed lists, which should translate into a free recall advantage for LF items.

\section{Method}

Participants and Design. Sixty university undergraduates participated in partial fulfillment of the requirements for an introductory psychology course. Word frequency was varied according to Erlebacher's (1977) method for comparing pure- versus mixed-list manipulations. Accordingly, there were three groups of participants: those given pure lists of HF words, those given pure lists of LF words, and those given mixed lists. Twenty participants were randomly assigned to each group. The participants were tested on personal computers in groups of 1 to 3 , and the experimental sessions lasted 20-30 min.

Materials. The stimuli were drawn from the item pool used by DeLosh and McDaniel (1996, Experiments 2 and 3). This item pool consists of 384 mono- or bisyllabic nouns selected from the Toglia and Battig (1978) semantic word norms. All the words ranged from four to eight letters in length and were of moderate to high imageability (range, 3.88-6.61). From this pool, $96 \mathrm{HF}$ words (occurrence greater than 60 per million) and $96 \mathrm{LF}$ words (occurrence less than 10 per million) were selected on the basis of the Francis and Kučera (1982) word frequency norms. Using these items, six HF lists and six LF word lists of 16 items each were constructed. Mixed lists were assembled by combining $8 \mathrm{HF}$ items from an $\mathrm{HF}$ list with $8 \mathrm{LF}$ items from an LF list. The remaining HF and LF words were combined to form a second set of mixed lists. Half of the participants in the mixed-list condition were given the first set of mixed lists, and the other half received the second set of mixed lists. Assignment of words to lists was random, with the constraint that the items in each list were orthographically, phonologically, and semantically dissimilar. The words were randomly assigned to the 16 serial positions for each list and each participant.

To verify that we were successful in constructing lists with low interitem associativity, we conducted a latent semantic analysis (LSA) of our word lists (Landauer \& Dumais, 1997). LSA is based on the natural tendency of words with similar meanings to occur in similar contexts (Howard \& Kahana, 2002). LSA vectors of 300 dimensions drawn from the TASA-All space ${ }^{2}$ were used to compute the semantic similarity of items within each list, defined as the cosine of the angle $\theta$ between vectors. A mean of these values was computed for each list (see Table 1) and then compared, using a Kruskal-Wallis test. This analysis revealed no significant difference in semantic similarity between pure HF, pure LF, and mixed lists $\left(\chi^{2}=3.53, p=.17\right)$.
Table 1

Results From the Latent Semantic Analysis of List Items

\begin{tabular}{clcc}
\hline & & \multicolumn{2}{c}{ Mean $\operatorname{Cos} \theta^{2}$} \\
\cline { 3 - 4 } & Condition & HF & LF \\
\hline \multirow{2}{*}{ Experiment 1} & Pure lists & .09 & .07 \\
& Mixed lists & $(.08)$ & $(.08)$ \\
Experiment 2 & Unrelated lists & .09 & .06 \\
& Related lists & .11 & .15 \\
\hline
\end{tabular}

Note-HF, high-frequency words; LF, low-frequency words.

In addition, an analysis of the lists was conducted using Nelson, McEvoy, and Schreiber's (1998) association norms. Although all of our HF words were included in these norms, many of our LF words were not; therefore, we limited our analysis to the HF lists. In our analysis, we examined all possible cue-target pairs from each list and tabulated the number of pairs that appeared as measurable forward associates in Nelson et al.'s norms. This analysis revealed that only 8 of the 1,440 pairs were listed as cue-target associates.

Procedure. The participants read instructions and completed a practice trial that described and demonstrated the free recall task. Note, however, that these instructions did not indicate that order memory would be tested, nor did they mention anything about attending to serial order information. After the practice trial had been completed, six experimental lists were given, with each list representative of the condition to which that participant was assigned (pure HF lists, pure LF lists, or mixed lists). Each list began with the word ready, accompanied by a brief tone. Then the 16 items constituting a list were presented one at a time in the center of the computer screen. Each item was shown for $1,500 \mathrm{msec}$, with $200 \mathrm{msec}$ between items. After each list, the participants engaged in $30 \mathrm{sec}$ of math problem distractor activity, with a tone signaling the end of this activity. Then they were given $60 \mathrm{sec}$ to write down all the words that they could recall on an answer sheet. A tone signaled the end of the 60 -sec free recall period.

After the free recall test for the final list, a serial order reconstruction test was given. Brief instructions were presented on the computer monitor. Then the 16 items from the most recent list were shown on the screen in a random arrangement. Using an answer sheet with 16 spaces labeled first through sixteenth, the participants were instructed to write the words shown on the computer screen in the response spaces on the basis of their memory for the order of presentation. They could begin with any item and fill in the spaces in any order but were required to fill in all 16 spaces without repeating any items. The participants were given as much time as needed to complete the task.

\section{Results and Discussion}

Order reconstruction. Scores representing the mean proportion correct in order reconstruction were submitted to a $2 \times 2$ ANOVA using Erlebacher's (1977) method, with word frequency (high vs. low) and list design (pure vs. mixed lists) as independent variables. An alpha level of .05 was used for this and all the other analyses reported in this study. No main effects were observed $(F \mathrm{~s}<2.4)$, but an interaction between frequency and design was obtained $\left[F(1,56)=4.00, M S_{\mathrm{e}}=0.02\right]$. In pure lists, order memory for HF words was significantly better than order memory for LF words $[t(38)=2.38, S E M=0.022]$, whereas in mixed lists, order memory did not differ $[t(19)<1]$ (see Table 2). Five participants in the mixed-list condition showed an advantage for HF words, 8 showed an advantage for LF words, and there were seven ties. This pattern 
Table 2

Order Reconstruction, Input-Output (I-O) Correspondence, and Free Recall as a Function of Word Frequency

\begin{tabular}{|c|c|c|c|c|c|c|}
\hline \multirow[b]{2}{*}{ Condition } & \multicolumn{2}{|c|}{ Reconstruction } & \multicolumn{2}{|c|}{$\begin{array}{c}\mathrm{I}-\mathrm{O} \\
\text { Correspondence } \\
\end{array}$} & \multicolumn{2}{|c|}{ Free Recall } \\
\hline & $\mathrm{HF}$ & $\mathrm{LF}$ & $\mathrm{HF}$ & $\mathrm{LF}$ & $\mathrm{HF}$ & $\mathrm{LF}$ \\
\hline \multicolumn{7}{|l|}{ Experiment 1} \\
\hline Pure lists & .29 & .19 & .67 & .59 & .47 & .31 \\
\hline Mixed lists & .24 & .25 & $(.59)$ & $(.59)$ & .35 & .39 \\
\hline \multicolumn{7}{|l|}{ Experiment 2A } \\
\hline Unrelated lists & .68 & .59 & .82 & .72 & .70 & .53 \\
\hline Related lists & .58 & .52 & .71 & .64 & .58 & .62 \\
\hline \multicolumn{7}{|l|}{ Experiment 2B } \\
\hline Related lists & .55 & .54 & .62 & .59 & .60 & .65 \\
\hline
\end{tabular}

reflects the fact that the order memory associated with HF words nominally decreased from pure lists to mixed lists, whereas the order memory associated with LF words nominally increased from pure lists to mixed lists.

Input-output correspondence. Next, we examined the extent to which recall protocols preserved stimulus presentation order, using Asch and Ebenholtz's (1962) index. This index represents the proportion of adjacent item pairs from the recall protocols that were in correct relative order, with a value of .50 indicating chance performance and 1.0 indicating perfect preservation of the presentation order. These scores were submitted to a between-subjects ANOVA with list type (pure HF vs. pure LF vs. mixed lists) as the independent variable. A significant effect was observed $\left[F(2,57)=3.41, M S_{\mathrm{e}}=0.01\right]$, so that input-output correspondence was greater for pure HF lists than for pure LF lists and mixed lists (means given in Table 2). All three input-output correspondence scores were significantly greater than would be expected by chance $[t \mathrm{~s}(19)=6.34$, 4.47, and 3.35 for HF, LF, and mixed lists, respectively].

Free recall. Recall scores were then submitted to a $2 \times$ 2 (frequency $\times$ list design) ANOVA using Erlebacher's (1977) technique. This analysis indicated that HF items were better recalled than LF items $[F(1,55)=14.25$, $\left.M S_{\mathrm{e}}=0.005\right]$. In addition, there was a significant interaction between word frequency and list design $[F(1,55)=$ $\left.36.74, M S_{\mathrm{e}}=0.005\right]$. In pure lists, $\mathrm{HF}$ words were recalled significantly better than LF words $[t(38)=5.60, S E M=$ 0.019 ]. The recall of HF words decreased from pure lists to mixed lists, however, whereas the recall of LF words increased from pure lists to mixed lists. This dynamic yielded a significant mixed-list advantage for LF words $[t(18)=2.32, S E M=0.015$; see Table 2 for means $]$. Four participants in the mixed-list condition exhibited better recall for HF words, eleven exhibited better recall for LF words, and there were five ties.

The results of Experiment 1 reveal that DeLosh and McDaniel's (1996) findings on the relation between order memory and free recall extend to longer lists and incidental order-encoding conditions. Input-output correspondence exceeded the level expected by chance for pure HF lists, pure LF lists, and mixed lists. It appears, then, that the participants encoded and used order information regardless of list composition, even though the order memory test was unexpected and 16-item lists were used. Moreover, measures of the retention and use of order information (i.e., order reconstruction and input-output correspondence) revealed an advantage for HF items in pure lists but no differences in mixed lists, as has been observed in previous work. Further paralleling past findings, free recall was better for HF items than for LF items when pure lists were compared, but the reverse was true when mixed lists were examined. This extension of DeLosh and McDaniel's findings to longer lists and incidental order-encoding conditions suggests that the order-encoding account may be more generally applicable to the existing literature on the word frequency effect.

The results are not, on the other hand, consistent with the idea that the word frequency effect is due to stronger preexperimental associations among HF items than among LF items (for a similar conclusion that is based on a close examination of word association norms, see Nelson \& McEvoy, 2000). Here, a pure-list free recall advantage for HF words was obtained even with HF lists consisting of a minimal number of direct associates. It appears, then, that Nelson and Xu's (1995) failure to obtain a significant HF advantage in recall may be explained by their use of mixed lists, rather than by their efforts to control for interitem associations. Note that an explanation based on preexperimental interitem associations also does not account for the observed free recall advantage for LF words in mixed lists. The set of LF words was not higher in preexisting semantic similarity than was the set of HF words, as indexed by the LSA metric.

\section{EXPERIMENT 2A}

Experiment 1 supports the view that order information is routinely encoded and used for free recall and that effects of word frequency on free recall reflect differences in order encoding as a function of list composition. Order memory for HF lists was better than order memory for LF lists, and this was associated with a free recall advantage for HF items. In mixed lists, order memory did not differ as a function of word frequency, and this was associated with a free recall advantage for LF items. 
A key prediction of the order-encoding account is that if participants are induced to use a retrieval strategy other than one based on serial order, the order memory advantage for HF lists should be inconsequential. If participants do not use order information to guide free recall, differences in order encoding should not affect recall performance. The induction of alternative retrieval strategies (other than one based on serial order) should, therefore, eliminate the pure-list free recall advantage for HF words. In fact, a strong prediction of the order-encoding framework is that alternative retrieval strategies should reverse the usual free recall advantage for HF items in pure lists.

As was outlined in the introduction, the order-encoding view proposes that $\mathrm{LF}$ items attract more individual-item processing than do HF items, due to their unusualness. It is this advantage in individual-item processing that confers a free recall advantage to LF items in mixed lists (when order memory is equivalent). In pure lists, the LF items are at a disadvantage with regard to order information, and this presumably overcomes the LF advantage in individual-item information, yielding better recall for $\mathrm{HF}$ items. This dynamic would not apply, however, if participants use a retrieval strategy other than one based on serial order. An alternative retrieval strategy that renders order information inconsequential would allow the LF advantage in individual-item information to be expressed as an advantage in free recall, even in pure lists, a reversal of the usual pattern. This is a strong test of the order-encoding account, because such a reversal has never been demonstrated in the word frequency literature.

One explanation of the recall advantage for LF items in mixed lists is that participants recognize the difficulty in learning uncommon items, relative to common items, and attempt to compensate for that difficulty by using more robust encoding strategies for the unusual items (Watkins, LeCompte, \& Kim, 2000). This view does not, however, predict an LF recall advantage in pure lists. We are not aware of any theories other than the order-encoding view that predict a reversal in pure-list recall, from an HF advantage with unrelated lists to an LF advantage in related lists. The present experiment tested this unique prediction of the order-encoding account by examining order memory and free recall for pure HF and pure LF lists consisting of semantically related items from ad hoc categories. As has been argued by Nairne et al. (1991), categorized or semantically related word lists furnish salient organizational information that is especially effective for guiding recall (see also Hunt \& Einstein, 1981). Participants are likely to use category labels or semantic associates as cues to generate retrieval candidates when related lists are given. Therefore, by using lists of semantically related items, we intended to induce a non-order-based retrieval strategy. In doing so, we predicted that order memory would be better for HF lists than for LF lists but that this advantage would not translate into better recall for HF items. Instead, we predicted that for pure lists of related items, LF words would be remembered better than HF words, due to the LF advantage in individual-item processing. We conducted two experiments to test these predictions; the participants were not explicitly informed about the semantic relations among the list items in Experiment 2A, whereas in Experiment 2B they were.

\section{Method}

Participants and Design. Sixty university undergraduates participated in partial fulfillment of an introductory psychology course requirement. Word frequency was manipulated within subjects but between lists. The relationship among list items was manipulated between subjects, with 30 participants randomly assigned to each of two conditions. In an unrelated-list condition, the participants were given lists of unrelated items, as in the first two experiments. In a related-list condition, lists consisted of words from ad hoc categories, such as things that are large and things associated with water. The participants were tested on personal computers in groups of 1-3 and experimental sessions lasted 40-50 min.

Materials. The item pool for the present experiment was generated by cross-referencing Whiteman's (1996) ad hoc category norms with Francis and Kučera's (1982) word frequency norms. A total of 192 nouns were selected, 96 of each frequency level. HF words had an occurrence greater than 60 per million, and LF words had an occurrence less than 10 per million, according to Francis and Kučera's norms. The items were among the 12 most frequently generated responses to the following ad hoc category labels: black, brown, cold, colorful, crawls, fast, first aid, fly, found in water, funny, fuzzy, green, hot, informative, large, long, loud, narrow, paper products, round, small, smelly, soft, and sweet (Whiteman, 1996). The 192 selected words were used to construct 12 pure HF lists and 12 pure LF lists, each consisting of eight items. For the related-list condition, the 8 words in each list belonged to the same ad hoc category. For the unrelated-list condition, the words from the related-list condition were pseudorandomly assigned to lists in such a way that the items in each list were orthographically, phonologically, and semantically dissimilar. For both conditions, the words were randomly assigned to the eight serial positions for each list and each participant. The participants were given all 24 lists, with the 12 lists of each frequency presented in blocked fashion and the order of the blocks counterbalanced across conditions.

As in Experiment 1, we used LSA to examine the semantic relatedness of our lists. For related lists, LF lists were higher in semantic association than were HF lists $[t(22)=2.42, p=.02$; see Table 2]. For unrelated lists, HF lists were more related than LF lists $[t(22)=$ $2.49, p=.02$; see Table 1]. Because of these differences, we conducted our analysis using data from all the lists, as well as a subset of lists that did not significantly differ in LSA scores (see the Results and Discussion section). A separate analysis of the lists, using Nelson et al.'s (1998) norms, revealed that related HF lists contained more direct forward associates (41) than did unrelated HF lists (5).

Procedure. The participants first read instructions that described the free recall and order reconstruction tasks; then they received one practice trial for each type of test. After these practice trials, the 24 experimental lists were presented. The list presentation method and testing technique followed that in DeLosh and McDaniel (1996). Each list began with the word ready, accompanied by a brief tone. Then the eight items making up a list were presented in the center of the computer monitor for $3 \mathrm{sec}$, with $500 \mathrm{msec}$ between items. After each list, the participants read rapidly presented random digits for $12 \mathrm{sec}$. Following this digit-shadowing distractor activity, the participants were given either a free recall test or an order reconstruction test, but not both. A random half of the HF and LF lists were followed by each type of test, and the participants had no prior knowledge of which test they would receive.

For the recall tests, the participants were given $60 \mathrm{sec}$ to write all of the words they could remember from the most recently presented list on an answer sheet. A tone signaled the end of the free recall period. For the order reconstruction tests, the eight items from the most recent list were simultaneously presented on the computer screen, 
but in random order. The participants' task was to reproduce the original presentation order of the list items. To do this, the participants rearranged the list items by selecting and placing them into an ordered series of boxes labeled first through eighth. This was accomplished by using arrow keys on the keyboard. The participants had to fill each box without placing a word in more than one box, guessing if necessary. They could respond in any order they wished and were given as much time as necessary to complete the task.

\section{Results and Discussion}

Order reconstruction. As in the previous experiment, for each participant, we calculated the mean proportion of words correctly placed in their original serial position. These scores were submitted to a $2 \times 2$ mixed ANOVA with word frequency as a within-subjects variable and word relation as a between-subjects variable. Overall, order memory was more accurate for HF lists (.63) than for $\operatorname{LF}$ lists $(.55)\left[F(1,58)=10.64, M S_{\mathrm{e}}=0.01\right]$. The main effect of word relation was marginally significant, with better order reconstruction performance for unrelated lists $(.63)$ than for related lists $(.55)[F(1,58)=$ $\left.2.92, M S_{\mathrm{e}}=0.07, p=.09\right]$. The interaction between word frequency and word relation did not approach significance $(F<1)$, since order reconstruction was consistently better for HF words than for LF words in both the unrelated- and the related-list conditions (see Table 2 for means). In the unrelated-list condition, 23 participants showed an advantage for HF words, and 7 showed an advantage for LF words. In the related-list condition, 17 participants had better order memory for HF words, 12 had better order memory for LF words, and there was one tie.

Input-output correspondence. Next, we conducted a mixed ANOVA on input-output correspondence scores. This analysis revealed significant effects of word frequency $\left[F(1,58)=21.17, M S_{\mathrm{e}}=0.01\right]$ and word relation $\left[F(1,58)=13.95, M S_{\mathrm{e}}=0.02\right]$. There was greater seriation for HF lists (.76) than for LF lists (.68) and for unrelated lists (.77) than for related lists (.67). As in the order reconstruction results, the interaction was not significant $(F<1)$, reflecting an advantage for HF over LF words in both the related- and the unrelated-list conditions (see Table 2 for means). For unrelated lists, 24 participants exhibited greater input-output correspondence for HF words, 5 exhibited greater input-output correspondence for LF words, and there was one tie. For related lists, 21 participants showed greater seriation for HF words, and 9 showed greater seriation for LF words. All input-output correspondence scores were significantly greater than would be expected by chance $[t s(29)>6]$.

Free recall. Next, we submitted recall scores to a $2 \times$ 2 mixed ANOVA. Overall, free recall was reliably better for HF lists (.64) than for LF lists $(.58)[F(1,58)=15.89$, $\left.M S_{\mathrm{e}}=0.01\right]$ but did not significantly differ as a function of word relation $\left[F(1,58)=0.22, M S_{\mathrm{e}}=0.04\right]$. There was, however, a significant interaction between word frequency and word relation $\left[F(1,58)=45.09, M S_{\mathrm{e}}=0.01\right]$. Free recall was better for HF words than LF words in unrelated lists $[t(29)=7.50, S E M=0.022]$. By contrast, free recall from related lists tended to be better for LF words than for HF words $[t(29)=1.95, S E M=0.022, p=.06$; see Table 2 for means]. For unrelated lists, 27 participants showed an advantage for HF words, 2 showed an advantage for LF words, and there was one tie. For related lists, 9 recalled more HF words, 18 recalled more LF words, and there were three ties.

As was described above, LSA analyses of our lists revealed that in the related condition, LF lists had higher LSA scores than did HF lists, whereas in the unrelated condition, LSA scores were higher for HF lists than for LF lists. This raised the possibility that our pattern of results was due to preexperimental associations, and not to the use of ad hoc categories. To address this issue, an additional analysis of the free recall data was conducted, using a subset of the original lists that were equated on LSA scores. For both the related and the unrelated conditions, 10 of the $12 \mathrm{HF}$ lists and 10 of the $12 \mathrm{LF}$ lists were selected. To arrive at lists similar in LSA scores $[M=.12$ and .13 for $\mathrm{HF}$ and LF related lists, respectively, and $[t(18)=1.64$, $p>.10 ; M=.08$ and .07 for HF and LF unrelated lists, respectively, and $t(18)=1.24, p>.10]$.

Free recall scores from this subset of lists were then submitted to a $2 \times 2$ mixed ANOVA, revealing a recall pattern identical to that observed with the full set of lists. Overall, free recall was reliably better for HF lists (.63) than for LF lists $(.57)\left[F(1,58)=15.04, M S_{\mathrm{e}}=0.01\right]$ but did not significantly differ as a function of word relation $\left[F(1,58)=0.48, M S_{\mathrm{e}}=0.04\right]$. There was, however, a significant interaction between word frequency and word relation $\left[F(1,58)=42.63, M S_{\mathrm{e}}=0.01\right]$. Free recall was better for HF words than for LF words in unrelated lists $[t(29)=7.06, S E M=0.024]$. By contrast, free recall from related lists tended to be better for LF words than for HF words $[t(29)=1.96, S E M=0.022, p=.06]$.

\section{EXPERIMENT 2B}

The primary intent of Experiment $2 \mathrm{~A}$ was to induce the participants to adopt a non-order-based retrieval strategy when lists consisted of semantically related words from ad hoc categories. Although input-output correspondence scores were significantly reduced for related-word lists, relative to unrelated-word lists, input-output correspondence scores were still quite high in the related-word condition, and there was still greater seriation in HF lists than in LF lists. Thus, our manipulation of the retrieval strategy may not have been as strong as intended, possibly reflecting our use of ad hoc categories. Because the participants were not notified of the ad hoc category structure of related-word lists, they may not have recognized them as such. We therefore administered the task to 30 new participants, giving them the ad hoc category labels for all related-word lists prior to study and recall. Providing the category label prior to list presentation may encourage participants to encode items as they relate to the category, and providing the category label once again at retrieval may encourage participants to use the category label to generate retrieval candidates (rather than use a seriation strategy). All other aspects of the experiment were identical to those in Experiment 2A. 


\section{Results and Discussion}

Order reconstruction. To compare order reconstruction scores for the new ad hoc category condition with those for the unrelated-word condition in Experiment 2A, a $2 \times 2$ mixed ANOVA was conducted with word frequency as a within-subjects variable and word relation as a between-subjects variable. Overall, order memory was more accurate for HF lists (.61) than for LF lists (.56) $\left[F(1,58)=5.66, M S_{\mathrm{e}}=0.01\right]$. The main effect of word relation approached significance, with better order reconstruction performance for unrelated-word lists (.63) than for related-word lists $(.55)\left[F(1,58)=3.40, M S_{\mathrm{e}}=0.06\right.$, $p=.07]$. The interaction between word frequency and word relation also approached significance $[F(1,58)=$ $\left.3.78, M S_{\mathrm{e}}=0.01\right]$, with a reliable difference between HF and LF lists in the unrelated condition $[t(29)=2.92$, $S E M=0.031]$, but not in the related condition $[t(29)<1$; see Table 2 for means]. In the unrelated-list condition, 23 participants showed an advantage for HF words and 7 showed an advantage for LF words. In the related-list condition, 16 participants had better order memory for HF words, 13 had better order memory for LF words, and there was one tie.

Input-output correspondence. Next, we conducted a mixed ANOVA on Asch-Ebenholtz (1962) input-output correspondence scores, using data from the related-list condition in Experiment 2B and the unrelated-list condition in Experiment 2A. Seriation was greater for $\mathrm{HF}$ lists $(.72)$ than for LF lists $(.66)\left[F(1,58)=13.03, M S_{\mathrm{e}}=\right.$ $0.01]$ and for unrelated-word lists $(.77)$ than for relatedword lists $(.61)\left[F(1,58)=38.33, M S_{\mathrm{e}}=0.02\right]$. The interaction was also significant, showing a reliable frequency effect in the unrelated-word condition $[t(29)=$ $3.69, S E M=0.026]$, but not in the related-word condition $[t(29)=1.20$; see Table 2 for means]. For unrelated lists, 24 participants exhibited greater input-output correspondence for HF words, 5 exhibited greater input-output correspondence for LF words, and there was one tie. For related lists, 15 participants showed greater seriation for HF words, 12 showed greater seriation for LF words, and there were three ties. All input-output correspondence scores were significantly greater than would be expected by chance $[t s(29)>3]$.

Free recall. A $2 \times 2$ mixed ANOVA on free recall scores (comparing the related-list condition from Experiment $2 \mathrm{~B}$ with the unrelated-list condition from Experiment $2 \mathrm{~A}$ ) showed that word retention was reliably better for HF lists (.65) than for LF lists $(.59)[F(1,58)=$ $\left.19.05, M S_{\mathrm{e}}=0.005\right]$ but did not significantly differ as a function of word relation $\left[F(1,58)=0.02, M S_{\mathrm{e}}=0.04\right]$. These findings were qualified by a significant interaction between word frequency and word relation $[F(1,58)=$ $\left.63.60, M S_{\mathrm{e}}=0.005\right]$. In unrelated-word lists, free recall was better for HF words than for LF words $[t(29)=7.50$, $S E M=0.022]$. The reverse pattern was observed in related lists, however, with better recall for LF items than for HF items $[t(29)=3.17$, $S E M=0.015$; means given in Table 2]. For unrelated lists, 27 participants showed an advantage for HF words, 2 showed an advantage for LF words, and there was one tie. For related lists, 6 recalled more HF words, 20 recalled more LF words, and there were four ties.

Using the same subset of lists as that used in Experiment $2 \mathrm{~A}$, we conducted an additional analysis of the free recall data, revealing the same pattern of results as that found with the full set of lists. A $2 \times 2$ mixed ANOVA showed that word retention was reliably better for HF lists (.64) than for LF lists $(.58)\left[F(1,58)=16.56, M S_{\mathrm{e}}=0.01\right]$ but did not significantly differ as a function of word relation $\left[F(1,58)=0.05, M S_{\mathrm{e}}=0.04\right]$. These findings were qualified by a significant interaction between word frequency and word relation $\left[F(1,58)=55.93, M S_{\mathrm{e}}=0.01\right]$. In unrelated-word lists, free recall was better for HF words than for LF words $[t(29)=7.06, S E M=0.024]$. The reverse pattern was observed in related lists, however, with better recall for LF items than for HF items $[t(29)=2.96$, $S E M=0.017]$.

As was outlined above, Experiments 2A and 2B were designed to induce participants to adopt a non-order-based retrieval strategy when given lists of semantically related words. Although input-output correspondence significantly exceeded what would be expected by chance for all the conditions, scores were significantly reduced for related lists, relative to unrelated lists, and the HF advantage in input-output correspondence was eliminated in Experiment $2 \mathrm{~B}$. This suggests that we were somewhat successful in diverting the participants to a non-order-based retrieval strategy in the related-list condition, especially in the second experiment. The order-encoding account uniquely predicts that under conditions of alternative strategy use, the order-encoding advantage for HF items should be inconsequential for recall. With order memory no longer an influential factor, the LF word advantage in individualitem information should be expressed as a pure-list advantage in free recall. In contrast, Watkins et al.'s (2000) compensatory strategy explanation for the LF recall advantage in mixed lists does not anticipate an LF advantage in related or unrelated pure lists. Other theories predict a pure-list HF advantage in both the unrelated- and the related-list conditions. Explanations based on accessibility propose that HF words are easier to access from semantic memory than are LF words. Explanations based on preexperimental interitem associations propose that $\mathrm{HF}$ items have an advantage in the number or strength of associations established prior to study (for further discussion of these theoretical approaches, see the General Discussion section). The use of related lists would not change the relative accessibility or preexperimental associativity of HF versus LF words, so by these accounts, the HF advantage in free recall should be maintained in related lists.

The results of Experiments $2 \mathrm{~A}$ and $2 \mathrm{~B}$ are consistent with the predictions of the order-encoding view. For both the unrelated- and the related-list conditions, order memory was better for HF lists than for LF lists. In the unrelated-list condition, HF lists yielded better recall than did LF lists, as has been observed in past experiments. However, in the related-list condition for which the use of order information was significantly reduced (as measured 
by input-output correspondence), recall was marginally (Experiment 2A) or significantly (Experiment 2B) better for LF items. This pure-list LF advantage in free recall is quite unique, having been obtained only once previously, in an experiment by Balota and Neely (1980) in which very long lists were used. Although this finding is novel, it is exactly the pattern anticipated by the order-encoding view.

Note that this reversal in the pattern of free recall reflects a significant increase in LF item recall, along with a significant decrease in HF item recall, from unrelated to related lists. The decline in free recall performance for HF items is particularly surprising from the perspective of traditional explanations of the word frequency effect. There is no principled reason to expect that the accessibility or preexperimental associativity of HF items would be reduced in related lists, relative to unrelated lists, especially given that associativity was increased in the related lists. This finding is also surprising on the basis of the existing memory literature. A common assumption is that the semantic organization afforded by related-word lists benefits free recall (cf. Hunt \& Einstein, 1981). Yet the recall of HF items was significantly reduced in our related-list condition, relative to our unrelated-list condition. This suggests that the alternative retrieval strategy induced by the inclusion of related items was less effective for HF word recall than was the seriation strategy used with unrelated items.

\section{GENERAL DISCUSSION}

The observation that words high in natural language occurrence are better recalled than words low in natural language occurrence is probably one of the best known and most accepted findings to emerge from the memory literature. Informal discussions with our colleagues in areas outside of cognitive psychology reveal that psychologists are usually familiar with the notion that common words are remembered better than uncommon words. In addition, judging by the paucity of research on the word frequency effect over the last 20 years, memory theorists appear to be comfortable that existing explanations of the effect offer satisfactory accounts. The present study demonstrates, however, that well-accepted ideas pertaining to the word frequency effect must be modified, as must existing explanations of the effect. We first will consider shortcomings of traditional theoretical accounts of the word frequency effect in light of the present data and then will amplify our more recent theoretical view as it relates to the present findings.

\section{Traditional Explanations of the Word Frequency Effect}

A classic explanation of the effect of word frequency on free recall is that HF words are more easily generated as retrieval candidates than are LF words, due to greater prior experience with HF items (cf. Nelson \& McEvoy, 2000). This explanation is based on the well-known spew principle, which states that the "availability of verbal units is directly related to the frequency with which the units have been experienced" (Underwood \& Schulz, 1960, p. 86). Although word frequency and accessibility tend to be correlated (Nelson \& McEvoy, 2000), an accessibility account cannot fully explain the effects of word frequency on free recall. For example, this view does not explain why the mnemonic advantage for HF words is eliminated in mixed lists, as was observed in Experiment 1 and numerous other studies (e.g., DeLosh \& McDaniel, 1996; Duncan, 1974; Gregg, 1976; Gregg et al., 1980; May \& Tryk, 1970). List composition cannot change the prior experience that presumably yields the HF advantage found in unmixed lists. Along similar lines, the accessibility view does not explain why the HF recall advantage is eliminated when related lists are used, as was observed in Experiments 2A and 2B. Likewise, an accessibility view cannot account for the decline in the level of recall for HF words from unmixed to mixed lists and from unrelated to related lists.

Another traditional explanation proposes that the effect of word frequency on free recall is mediated by preexperimental interitem associations, with HF words benefiting from stronger or more numerous associations than do LF words (Deese, 1960; Gregg, 1976; Nelson \& Xu, 1995). One idea, for example, is that preexperimental associations are more firmly established among HF words than among LF words, due to more frequent co-occurrence of HF items in past experience (Stuart \& Hulme, 2000). Recent work by Nelson and Zhang (2000) shows that associations established before study trials dramatically influence episodic recall levels, presumably because a recalled target can effectively cue retrieval of associated targets. This could potentially account for HF word advantages in free recall, because measures of average interitem association strength are reported to be greater for HF words than for LF words (e.g., Deese, 1960; Gregg, 1976; but see Nelson \& McEvoy, 2000). This view could also account for the decline in recall for HF words from pure to mixed lists by assuming that replacement of HF words with LF words reduces the number of opportunities for HF targets to be recalled on the basis of prior associations.

The present study raises problems for an associativity account in several respects. First, the lists used in the present experiments comprised items with a minimal number of direct associates and similar semantic relatedness, yet we replicated the usual effects of word frequency on free recall, suggesting that preexperimental associations do not play a critical role in the word frequency effect (for a similar conclusion, see Nelson \& McEvoy, 2000). Second, an associativity account does not explain the recall advantage for LF words in pure-related lists or mixed lists. LF words are presumably low in average interitem association strength and should, therefore, be less strongly related to potential cues (recalled words or extralist words that come to mind) than are HF words. Third, an associativity account does not explain the significant decline in HF word recall from unrelated to related lists, as observed in Experiments 2A and 2B. According to Nelson et al.'s (1998) association norms, there was an eightfold increase 
in the number of direct associates for related HF lists, relative to unrelated HF lists. If anything, then, an explanation based on preexperimental associations would expect better recall of HF words from related lists than of those from unrelated lists; yet we observed the opposite pattern.

One account that directly attempts to explain word frequency effects as a function of list composition was proposed by Gillund and Shiffrin (1984) in the context of the search of associative memory (SAM) model. According to this view, HF words have stronger associative relations to other items than do LF words, both in terms of prior associations (represented by a residual association parameter) and in terms of experimental associations formed during study (represented by an interitem association parameter). Consequently, $\mathrm{HF}$ words are assumed to be more effective cues than are LF words. Because the SAM model assumes that retrieval candidates are activated by a cue constellation that includes previously recalled items, this would produce better recall for pure lists of HF words than for pure lists of LF words. In mixed lists, on the other hand, recalled HF words have the opportunity to cue LF words, thereby improving the recall of LF words in mixed lists, relative to pure lists. Conversely, recalled LF words serve as cues for HF words, thereby decreasing the recall of $\mathrm{HF}$ words in mixed lists, relative to pure lists. As such, this view can explain the changes in level of recall for HF and LF words in pure versus mixed lists and explicitly predicts that the HF word advantage in pure lists will be eliminated in mixed lists. Note, however, that SAM also predicts that the overall level of recall in mixed lists will directly vary with the proportion of HF items in the list (Gillund \& Shiffrin, 1984, p. 36) and that, regardless of the proportion of HF items, recall for HF and LF words should be equivalent. DeLosh and McDaniel (1996, Experiment 3) were unable to confirm these predictions. Higher proportions of HF words in mixed lists did not significantly improve overall list recall, and for all types of mixed lists that were used in their experiment, LF words were recalled significantly better than HF words.

The present study revealed another result that is difficult to reconcile with Gillund and Shiffrin's (1984) explanation. By their view, one would expect that when items are conceptually related (as in the related-list conditions of Experiments 2A and 2B), recall for pure lists of $\mathrm{HF}$ items should be as good as, if not better than, a condition in which items are unrelated. Cue values for HF words should be just as strong in related lists as in unrelated lists and may be enhanced if the conceptual relations between items promote joint rehearsal of list words. Yet we found that the recall of HF words was significantly reduced for related lists, relative to unrelated lists. Note that this effect could not be due to general interference caused by the ad hoc relations, because the recall of LF items improved for related lists, relative to unrelated lists, and in Experiment 2B, recall of LF items significantly surpassed recall of HF items. Just as surprising, from the perspective of the SAM account, was our finding that recall for pure lists of LF words was better than recall for pure lists of HF words in the related-list condition. More generally, the relatively poor recall of HF words from pure related lists is completely unexpected from any existing view of which we are aware (other than the order-encoding account), and it is not clear how existing views could explain this finding, even in a post hoc fashion.

\section{The Order-Encoding Account}

The appeal of the order-encoding account is that it explicitly anticipated the novel finding that LF words would be better recalled than HF words when pure lists of related items were given. As has been developed in the previous sections, the idea is that the typical HF advantage in free recall reflects the encoding and use of serial order information, with HF lists enjoying an advantage over LF lists in the encoding of this type of organizational information. When other salient forms of relational information are present (e.g., semantic or categorical relations), serial order information has a diminished role in guiding free recall (cf. Nairne et al., 1991). In this situation, the HF list advantage in the encoding of serial order information is inconsequential for recall. As a result, LF items are recalled as well as or better than HF items because the LF items benefit from use of organizational information (semantic and categorical relations in this case) and continue to enjoy their advantage in the encoding of individualitem information (cf. Hunt \& McDaniel, 1993).

The surprising finding of a significant decline in recall for HF words from related lists to unrelated lists can also be explained by the order-encoding view. One needs to assume only that the ad hoc relational information in related HF lists does not provide as strong of an organizational scheme as the serial order information in unrelated HF lists (cf. Einstein \& Hunt, 1980).

The present study also revealed several additional findings that inform the order-encoding view. Previous work by DeLosh and McDaniel (1996) was based on short lists of 8 items, raising the issue of the extent to which order encoding plays a role in the word frequency effects found with longer lists. On this issue, the results from Experiment 1 indicated that the pattern of order memory, input-output correspondence, and free recall anticipated by the orderencoding view is obtained with a more typical list length of 16 items. Other studies have suggested that the orderencoding framework may apply to still longer lists. In the generation effect literature, for example, Burns (1996, Experiment 1) obtained the predicted association between order memory and free recall (i.e., a read advantage on both measures) with 40-item lists. More generally, Mandler and Dean (1969) obtained results suggesting that seriation is the preferred method for organizing lists up to 50 items in length. Order encoding may, of course, play less of a role in free recall for very long lists than for short lists. For instance, Engelkamp and Dehn (2000) found that serial order retention was minimal for 24-item lists of performed actions.

Another limitation of the previous work by DeLosh and McDaniel (1996) is that the participants knew order memory would be tested, perhaps encouraging encoding and retrieval strategies that would not ordinarily be recruited in a traditional free recall experiment. In the present study, 
even when the participants were given no indication that order memory tests were forthcoming, we obtained the full complement of order memory and free recall results expected by the order-encoding view. Comparable results have been obtained in studies of other phenomena for which serial order memory has been implicated. Using an incidental-learning protocol, Serra and Nairne (1993, Experiment 3) observed that order memory was better for read items than for generated items in pure lists but that order memory did not differ in mixed lists. Likewise, McDaniel et al. (1995, Experiment 4) used an incidentallearning procedure and found that order memory was better for common items than for bizarre items in pure lists but was equivalent in mixed lists. More generally, Toglia and Kimble (1976) found that order memory (as measured by serial position judgments) was just as accurate when the order test was unexpected as when the order test was expected. Thus, the pattern of order memory and free recall anticipated by the order-encoding account is not limited to intentional order-encoding conditions, suggesting that this account may be more generally applied to documented word frequency effects.

As was indicated in the introduction (see also McDaniel et al., 2000), one advantage of the order-encoding view is that it may be useful for understanding several phenomena in the memory literature, including the effects of generation and bizarreness, in addition to the word frequency effect. The present study reveals intriguing parallels between our word frequency results and findings in these other areas, some of which were described above. Most notably, our findings with related versus unrelated lists mirror those obtained with comparable manipulations in the generation effect literature. In that literature, the typical finding is that pure lists of read words are recalled as well as (Begg \& Snider, 1987; Hirshman \& Bjork, 1988; McDaniel, Waddill, \& Einstein, 1988; Serra \& Nairne, 1993; Slamecka \& Katsaiti, 1987) or better than (Nairne et al., 1991; Schmidt \& Cherry, 1989) generated words when lists of unrelated items are used. In accord with an order-encoding approach, read items are also associated with better order memory and input-output correspondence (Nairne et al., 1991; Serra \& Nairne, 1993). When lists comprise categorically related items, however, pure lists of generated items yield better recall than do pure lists of read items (Burns, 1996; McDaniel et al., 1988). Paralleling the LF advantage obtained with related lists in Experiment 2B, this pure-list generation effect also occurs with ad hoc category relations (McDaniel, Riegler, $\&$ Waddill, 1990). Further paralleling the results of Experiments $2 \mathrm{~A}$ and $2 \mathrm{~B}$, the pure-list generation effect is accompanied by lower order reconstruction scores and input-output correspondence for related lists than for unrelated lists (Nairne et al., 1991). In general, then, when pure lists of items that are associated with better individual-item encoding (as revealed by superior recognition performance) are compared with pure lists of items that are associated with better serial order encoding under conditions that provide a non-order-based organizational scheme, the encoding and use of order information in free recall is reduced. Concomitantly, free recall is reversed, from an advantage for those items associated with better serial order encoding (HF words and read items) to an advantage for those items associated with better individualitem encoding ( $\mathrm{LF}$ words and generated items), consistent with an explanation based on the encoding of serial order information.

In addition, the order-encoding view can explain the LF advantage in recognition memory that is observed in both pure- and mixed-list designs. As was outlined in the introduction, the order-encoding view assumes that LF items have an advantage in item memory. Many studies support this assumption. In the well-studied mirror effect, LF items are usually associated with higher hit rates but generate fewer false alarms (Glanzer \& Adams, 1985). Interestingly, the memorial advantage for LF items increases as the proportion of LF list items decreases, which serves to increase the unusualness of LF items (Malmberg \& Murnane, 2002). Other evidence indicates that the mirror effect may be directly tied to encoding of distinctive features (Criss \& Shiffrin, 2004). Recent physiological evidence also demonstrates that LF items attract more attention and that this attention is associated with improvements in recognition memory (de Zubicaray, McMahon, Eastburn, Finnigan, \& Humphreys, 2005). According to the order-encoding view, the apparent LF advantage in item memory should produce an LF advantage in recognition memory, regardless of list composition, because the HF advantage in order memory would presumably have little consequence in recognition tasks.

Future research is needed, however, to further examine the construct of order memory and the possible dissociations between different types of order memory. In this and previous studies, we (and others) have tended to treat order information as a unitary construct. Although we acknowledge that there are different types of order information, the relationship between individual-item information and order information may require a more nuanced approach in the future. It may be the case, for example, that unusualness has a particularly potent effect on the encoding and use of relative order information but a different effect on the encoding and use of absolute order information (e.g., Nairne \& Kelley, 2004). In fact, when a single unusual item is included in a list, memory for list position is superior for that item than for the other items in the list (Kelley \& Nairne, 2001). Although we did not investigate this question here, future research should consider this important issue.

This need for further research notwithstanding, past and present studies on the order-encoding view demonstrate that serial order information can play an important role in the long-term retention of items or events that are processed sequentially. Serial order information has received relatively little empirical attention over the last 2 decades and is rarely discussed in theoretical treatments of long-term memory phenomena. Informal discussions with other memory researchers suggest that this lack of attention reflects a common presumption that order retention is less important than such factors as semantic orga- 
nization and elaboration, especially in the realm of longterm memory. However, the present line of research shows that the retention of order information has reliable and systematic effects on long-term free recall and suggests that theoretical approaches based on the joint influence of individual-item and serial order encoding may be fruitful in accounting for a wide variety of memory phenomena.

\section{REFERENCES}

Asch, S. E., \& Ebenholtz, S. M. (1962). The process of free recall: Evidence for non-associative factors in acquisition and retention. Journal of Psychology: Interdisciplinary \& Applied, 54, 3-31.

Balota, D. A., \& NeEly, J. H. (1980). Test-expectancy and wordfrequency effects in recall and recognition. Journal of Experimental Psychology: Human Learning \& Memory, 6, 576-587.

BEGG, I., \& SNIDER, A. (1987). The generation effect: Evidence for generalized inhibition. Journal of Experimental Psychology: Learning, Memory, \& Cognition, 13, 553-563.

BuRNS, D. J. (1992). The consequences of generation. Journal of Memory \& Language, 31, 615-633.

BURNS, D. J. (1996). The item-order distinction and the generation effect: The importance of order information in long-term memory. American Journal of Psychology, 109, 567-580.

Burns, D. J., CurTI, E. T., \& LAVIN, J. C. (1993). The effects of generation on item and order retention in immediate and delayed recall. Memory \& Cognition, 21, 846-852.

CRISS, A. H., \& SHIFFrIN, R. M. (2004). Interactions between study task, study time, and the low-frequency hit rate advantage in recognition memory. Journal of Experimental Psychology: Learning, Memory, \& Cognition, 30, 778-786.

DEESE, J. (1960). Frequency of usage and number of words in free recall: The role of association. Psychological Reports, 7, 337-344.

DeLosh, E. L., \& McDaniel, M. A. (1996). The role of order information in free recall: Application to the word-frequency effect. Journal of Experimental Psychology: Learning, Memory, \& Cognition, 22, 1136-1146.

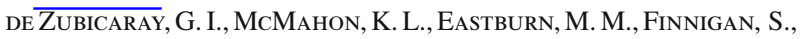
\& Humphreys, M. S. (2005). fMRI evidence of word frequency and strength effects during episodic memory encoding. Cognitive Brain Research, 22, 439-450.

DunCAN, C. P. (1974). Retrieval of low-frequency words from mixed lists. Bulletin of the Psychonomic Society, 4, 137-138.

EInstein, G. O., \& Hunt, R. R. (1980). Levels of processing and organization: Additive effects of individual-item and relational processing. Journal of Experimental Psychology: Human Learning \& Memory, 6, 588-598.

ENGELKAMP, J., \& DeHN, D. M. (2000). Item and order information in subject-performed tasks and experimenter-performed tasks. Journal of Experimental Psychology: Learning, Memory, \& Cognition, 26, 671-682.

ERLEBACHER, A. (1977). Design and analysis of experiments contrasting the within- and between-subjects manipulation of the independent variable. Psychological Bulletin, 84, 212-219.

Estes, W. K. (1972). An associative basis for coding and organization in memory. In A. W. Melton \& E. Martin (Eds.), Coding processes in human memory (pp. 161-190). Washington, DC: Winston.

Francis, W. N., \& KuČERA, H. (1982). Frequency analysis of English usage: Lexicon and grammar. Boston: Houghton Mifflin.

Gillund, G., \& Shiffrin, R. M. (1984). A retrieval model for both recognition and recall. Psychological Review, 91, 1-67.

GlanZer, M., \& AdAMs, J. K. (1985). The mirror effect in recognition memory. Memory \& Cognition, 13, 8-20.

Golly-Häring, C., \& ENGElKAMP, J. (2003). Categorical-relational and order-relational information in memory for subject-performed and experimenter-performed actions. Journal of Experimental Psychology: Learning, Memory, \& Cognition, 29, 965-975.

GREENE, R. L. (1989). Immediate serial recall of mixed-modality lists. Journal of Experimental Psychology: Learning, Memory, \& Cognition, 15, 266-274.
GREGG, V. H. (1976). Word frequency, recognition, and recall. In J. Brown (Ed.), Recall and recognition (pp. 183-216). London: Wiley.

GregG, V. H., Montgomery, D. C., \& Castaño, D. (1980). Recall of common and uncommon words from pure and mixed lists. Journal of Verbal Learning \& Verbal Behavior, 19, 240-245.

HALL, J. F. (1954). Learning as a function of word frequency. American Journal of Psychology, 67, 138-140.

HALL, J. W. (1992). Unmixing effects of spacing on free recall. Journal of Experimental Psychology: Learning, Memory, \& Cognition, 18, 608-614.

Healy, A. F. (1974). Separating item from order information in shortterm memory. Journal of Verbal Learning \& Verbal Behavior, 13, 644-655.

HINRICHS, J. V. (1970). A two-process memory-strength theory for judgment of recency. Psychological Review, 77, 223-233.

Hirshman, E. (1988). The expectation-violation effect: Paradoxical effects of semantic relatedness. Journal of Memory \& Language, 27, $40-58$.

HiRSHMAN, E., \& BJork, R. A. (1988). The generation effect: Support for a two-factor theory. Journal of Experimental Psychology: Learning, Memory, \& Cognition, 14, 484-494.

HowaRD, M. W., \& Kahana, M. J. (2002). When does semantic similarity help episodic retrieval? Journal of Memory \& Language, 46, $85-98$.

HUNT, R. R., \& Einstein, G. O. (1981). Relational and item-specific information in memory. Journal of Verbal Learning \& Verbal Behavior, 20, 497-514.

Hunt, R. R., \& ElLiott, J. M. (1980). The role of nonsemantic information in memory: Orthographic distinctiveness effects on retention. Journal of Experimental Psychology: General, 109, 49-74.

HUNT, R. R., \& MCDANIEL, M. A. (1993). The enigma of organization and distinctiveness. Journal of Memory \& Language, 32, 421-445.

Kelley, M. R., \& NAIRNE, J. S. (2001). von Restorff revisited: Isolation, generation, and memory for order. Journal of Experimental Psychology: Learning, Memory, \& Cognition, 27, 54-66.

KINTSCH, W. (1970). Models for free recall and recognition. In D. A. Norman (Ed.), Models of human memory (pp. 331-373). New York: Academic Press.

Landauer, T. K., \& Dumais, S. T. (1997). A solution to Plato's problem: The latent semantic analysis theory of acquisition, induction, and representation of knowledge. Psychological Review, 104, 211-240.

Malmberg, K. J., \& MurnAne, K. (2002). List composition and the word-frequency effect for recognition memory. Journal of Experimental Psychology: Learning, Memory, \& Cognition, 28, 616-630.

MalmberG, K. J., \& Nelson, T. O. (2003). The word frequency effect for recognition memory and the elevated-attention hypothesis. Memory \& Cognition, 31, 35-43.

MANDLER, G. (1969). Input variables and output strategies in free recall of categorized lists. American Journal of Psychology, 82, 531-539.

Mandler, G., \& Dean P. J. (1969). Seriation: Development of serial order in free recall. Journal of Experimental Psychology, 81, $207-$ 215.

MAY, R. B., \& TRYK, H. E. (1970). Word sequence, word frequency, and free recall. Canadian Journal of Psychology, 24, 299-304.

McDaniel, M. A., DeLosh, E. L., \& Merritt, P. S. (2000). Order information and retrieval distinctiveness: Recall of common versus bizarre material. Journal of Experimental Psychology: Learning, Memory, \& Cognition, 26, 1045-1056.

MCDANIEL, M. A., \& EINSTEIN, G. O. (1986). Bizarre imagery as an effective memory aid: The importance of distinctiveness. Journal of Experimental Psychology: Learning, Memory, \& Cognition, 12, 54-65.

MCDaniel, M. A., Einstein, G. O., Delosh, E. L., May, C. P., \& BRADY, P. (1995). The bizarreness effect: It's not surprising, it's complex. Journal of Experimental Psychology: Learning, Memory, \& Cognition, 21, 422-435.

MCDANIEL, M. A., RIEGLER, G. L., \& WAdDILl, P. J. (1990). Generation effects in free recall: Further support for a three-factor theory. Journal of Experimental Psychology: Learning, Memory, \& Cognition, 16, 789-798

MCDANIEL, M. A., WAdDill, P. J., \& Einstein, G. O. (1988). A contextual account of the generation effect: A three-factor theory. Journal of Memory \& Language, 27, 521-536. 
Mulligan, N. W. (1999). The effects of perceptual interference at encoding on organization and order: Investigating the roles of itemspecific and relational information. Journal of Experimental Psychology: Learning, Memory, \& Cognition, 25, 54-69.

Mulligan, N. W. (2000a). Perceptual interference and memory for order. Journal of Memory \& Language, 43, 680-697.

MULLIGAN, N. W. (2000b). Perceptual interference at encoding enhances item-specific encoding and disrupts relational encoding: Evidence from multiple recall tests. Memory \& Cognition, 28, 539-546.

Mulligan, N. W. (2001). Word frequency and memory: Effects on absolute versus relative order memory and on item memory versus order memory. Memory \& Cognition, 29, 977-985.

Mulligan, N. W. (2002). The generation effect: Dissociating enhanced item memory and disrupted order memory. Memory \& Cognition, 30, 850-861.

MURDOCK, B. B., JR. (1974). Human memory: Theory and data. Hillsdale, NJ: Erlbaum.

NAIRne, J. S., \& Kelley, M. R. (2004). Separating item and order information through process dissociation. Journal of Memory \& Language, 50, 113-133.

NAirne, J. S., Riegler, G. L., \& SERRA, M. (1991). Dissociative effects of generation on item and order retention. Journal of Experimental Psychology: Learning, Memory, \& Cognition, 17, 702-709.

NELSON, D. L., \& MCEVOY, C. L. (2000). What is this thing called frequency? Memory \& Cognition, 28, 509-522.

Nelson, D. L., McEvoy, C. L., \& SchreIBER, T. A. (1998). The University of South Florida word association, rhyme, and word fragment norms [Online]. Available at www.usf.edu/FreeAssociation.

Nelson, D. L., \& XU, J. (1995). Effects of implicit memory on explicit recall: Set size and word-frequency effects. Psychological Research, 57, 203-214

NELSON, D. L., \& ZhANG, N. (2000). The ties that bind what is known to the recall of what is new. Psychonomic Bulletin \& Review, 7, 604-617.

Postman, L. (1970). Effects of word frequency on acquisition and retention under conditions of free-recall learning. Quarterly Journal of Experimental Psychology, 22, 185-195.

Postman, L. (1972). A pragmatic view of organization theory. In E. Tulving \& W. Donaldson (Eds.), Organization of memory (pp. 3-48). New York: Academic Press.

RANSDELL, S. E., \& FISCHLER, I. (1989). Effects of concreteness and task context on recall of prose among bilingual and monolingual speakers. Journal of Memory \& Language, 28, 278-291.

ScHMIDT, S. R. (1994). Effects of humor on sentence memory. Journal of Experimental Psychology: Learning, Memory, \& Cognition, 20, 953-967.

SCHMIDT, S. R., \& CHERry, K. (1989). The negative generation effect: Delineation of a phenomenon. Memory \& Cognition, 17, 359-369.

Serra, M., \& NAIRNE, J. S. (1993). Design controversies and the generation effect: Support for an item-order hypothesis. Memory \& Cognition, 21, 34-40.

SlAMECKA, N. J., \& Katsaiti, L. T. (1987). The generation effect as an artifact of selective displaced rehearsal. Journal of Memory \& Language, 26, 589-607.

StUART, G., \& HUlME, C. (2000). The effects of word co-occurence on short-term memory: Associative links in long-term memory affect short-term memory performance. Journal of Experimental Psychology: Learning, Memory, \& Cognition, 26, 796-802.

SuMBY, W. H. (1963). Word frequency and serial position effects. Journal of Verbal Learning \& Verbal Behavior, 1, 443-450.

Toglia, M. P., \& BatTig, W. F. (1978). Handbook of semantic word norms. Hillsdale, NJ: Erlbaum.

Toglia, M. P., \& Kimble, G. A. (1976). Recall and use of serial position information. Journal of Experimental Psychology: Human Learning \& Memory, 2, 431-445.

Tulving, E., \& Madigan, S. A. (1970). Memory and verbal learning. Annual Review of Psychology, 21, 437-484.

TZENG, O. J. L. (1976). A precedence effect in the processing of verbal information. American Journal of Psychology, 89, 577-599.

Tzeng, O. J. L., LEe, A. T., \& WeTZEL, C. D. (1979). Temporal coding in verbal information processing. Journal of Experimental Psychology: Human Learning \& Memory, 5, 52-64.

UNDERWOOD, B. J. (1969). Attributes of memory. Psychological Review, 76, 559-573

UNDERWOOD, B. J., \& SCHULZ, R. W. (1960). Meaningfulness and verbal learning. Chicago: Lippincott.

WatKins, M. J., LeCompte, D. C., \& Kim, K. (2000). Role of study strategy in recall of mixed lists of common and rare words. Journal of Experimental Psychology: Learning, Memory, \& Cognition, 26, 239-245.

WHITEMAN, H. L. (1996). Ad-hoc category norms. Unpublished raw data. Whiteman, H. L., Nairne, J. S., \& Serra, M. (1994). Recognition and recall-like processes in the long-term reconstruction of order. Memory, 2, 275-294.

ZuCCO, G., BARDESANO, T. A., \& CoRNOLDI, C. (1984). Il ruolo di dettagli non essenziali e della loro predicibilità contestuale nella rievocazione di nomi di figure [The role of nonessential details and of their contextual predictability in the recall of names of pictures]. Ricerche di Psicologia, 8, 43-58.

\section{NOTES}

1. Note, however, that Whiteman, Nairne, and Serra (1994) did not consistently obtain this order memory pattern. As described by DeLosh and McDaniel (1996), this failure to consistently find a pure-list HF word advantage in order reconstruction may reflect their experimental protocol, whereby participants were given a randomly ordered mixture of HF and LF lists.

2. All values were obtained from the Latent Semantic Analysis @ CU Boulder interface at lsa.colorado.edu/.

(Manuscript received March 15, 2005; revision accepted for publication September 17, 2005.) 